\title{
Let it go
}

Choon How How, MMed, FCFP

I am honoured to announce that the first themed issue of Singapore Medical Journal (SMJ) in 2014 is an issue featuring family medicine. In themed issues, original papers that best showcase the topic at hand are collated together with invited articles.

I would like to take this opportunity to express my gratitude to the highly respected teachers, seniors, and friends who have kindly accepted invitations to write and review articles, sharing their wisdom on the healthcare landscape of Singapore and the different challenges faced by family medicine. These articles contain gems in the fields of clinical services, ${ }^{(1,2)}$ recent policy developments, ${ }^{(1,3)}$ education $^{(4)}$ and healthcare integration initiatives, ${ }^{(2,3)}$ illuminating the achievements of family medicine from the past right into the future. There are many recurrent themes, important lessons and ongoing discussions in these articles that will determine how the healthcare community can deliver better value for patients (e.g. through better integration initiatives, the strengthening of our primary healthcare, and collaboration for population health in the community).

Even as Singapore's healthcare performance becomes comparable with that of OECD (Organisation for Economic Cooperation and Development) countries, ${ }^{(5)}$ we know that there is room for improvement. Soo and Tan studied how caregivers' perceptions can affect their help-seeking behaviour and care of children with asthma, ${ }^{(6)}$ while Chia and Lian interviewed parents on their knowledge of infant basic life support and recommended that the gaps in knowledge be bridged through formal training and regular refresher courses. ${ }^{(7)}$

With obesity and unhealthy lifestyles on the rise, Tan and Wong share their experience in helping patients lose weight through a nonsurgical weight management programme, ${ }^{(8)}$ and Tan et al present findings on whether primary care physicians 'walk their talk' with regard to healthy living habits and other preventive health measures. ${ }^{(9)}$ Furthermore, although respiratory infections continue to threaten and plague Singapore, the local community appears resistant to the use of facemasks to contain the aerosol spread of diseases. This problem is discussed in a literature review by Sim et al, in which the authors share their recommendations on how to start promoting the use of facemasks in Singapore. ${ }^{(10}$

This themed issue also features an interesting finding of a higher local incidence of discontinuation of ACE inhibitors due to cough. ${ }^{(11)}$ In that study, $\mathrm{Ng}$ and Goh proposed that the choice of antihypertensive or renal protective medications can be reconsidered in light of their findings.

Finally, I would like to thank the wonderful editorial team at $S M J$ for their help in making this issue possible. The publication of this theme issue is a milestone achievement for family medicine in Singapore; it marks the maturity of the discipline in the many fronts of clinical services, integrative care, education and research. With the focus on strengthening integration efforts and transforming primary care in the communities, I am confident that family medicine is ready to 'Let it $\mathrm{go}^{\prime}{ }^{(9)}$

\section{REFERENCES}

1. Tan NC. PAIR UP for primary care excellence: perspectives from a primary healthcare provider in Singapore. Singapore Med J 2014; 55:100-16.

2. How CH, Fock KM. Healthcare in Singapore: the present and future. Singapore Med J 2014; 55:126-7.

3. Cheong PY. Education and training in family medicine: looking ahead. Singapore Med J 2014; 55:124-5.

4. Goh LG, Ong CP. Education and training in family medicine: progress and a proposed national vision for 2030. Singapore Med J 2014; 55:117-23.

5. OECD iLibrary. Health at a Glance 2013: OECD Indicators [online]. Available at: http://dx.doi.org/10.1787/health_glance-2013-en. Accessed February 28, 2014.

6. Soo WF, Tan NC. The influence of caregivers' knowledge and understanding of asthma aetiology on domiciliary management of children with asthma. Singapore Med J 2014; 55:132-6.

7. Chia P, Lian WB. Parental knowledge, attitudes and perceptions regarding infant basic life support. Singapore Med J 2014; 55:137-45

8. Tan WJ, Wong TK. Demographic profile, clinical characteristics, motivations and weight loss outcomes of patients participating in a nonsurgical weight management programme. Singapore Med J 2014; 55:150-4.

9. Tan NC, Aw LF, Khin LW, et al. How do primary care physicians in Singapore keep healthy? Singapore Med J 2014; 55:155-9.

10. Sim SW, Moey KS, Tan NC. The use of facemasks to prevent respiratory infection: a literature review in the context of the Health Belief Model. Singapore Med J 2014; 55:160-7.

11. Ng LP, Goh P. Incidence of discontinuation of angiotensin-converting enzyme inhibitors due to cough in a primary healthcare centre in Singapore. Singapore Med J 2014; 55:146-149.

12. Menzel I. "Let it go." By Kristen Anderson-Lopez, Robert Lopez. Frozen (Original Motion Picture Soundtrack). Walt Disney, 2013. 